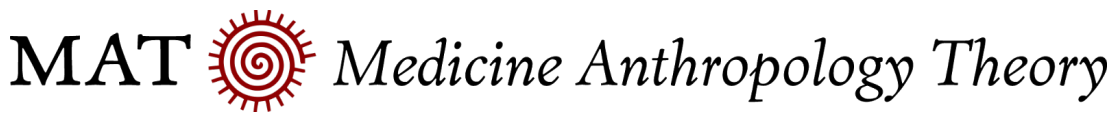

EDITORIAL

\section{Disciplinary limits}

MAT Editorial Collective

When we wrote the last editorial back in September 2020, we could not have imagined that we would be in the bio-political situation we find ourselves in today. Locked down as we have been these last three months and with our phenomenological perception of time duly affected, already it has become difficult to remember that, back then, COVID-19 vaccines were still in the trial phases of development and our current present was but one possible future among many. As spring begins to take the edge off the long winter here in Edinburgh, we live the hopes and fears of the widespread vaccination programme. Over half the population of the United Kingdom (UK) has now received their first vaccine. For many of us, our emergence from the second long lockdown has meant facing the intensity of managing the second semester of the teaching year from home while being spatially separated from those we love and with children who have for long periods been off from school. Both the virus and our containment responses to it continue to wreak havoc to the interstices of the social fabrics that mould us. In this context, we pause here to offer all of you involved with the running of MAT our profound thanks: for your patience, your forbearance, and the labour that you have contributed to making our vision for the journal come to life. Without all of your help-as authors, reviewers, staff, editors, advisors and committee membersthrough these trying times, we would not have been able to bring this edition to light. 
Yet here in the UK, we are in many ways fortunate. Many countries grapple with further waves of infection and lockdown, mired in situations that remain volatile and by no means certain. The politics of the present is now suffused with issues around 'vaccine nationalism' and questions around the production, regulation, and distribution of vaccines. For many, the lines of social and racial inequalities that were exposed by the spread of the virus are now being repeated around vaccine access. In the press and media, we are bombarded with scientific debates on questions of efficacy, complex potential associations of rare side effects, population-based statistics, and questions of burgeoning vaccine hesitancy. As anthropologists, we are called to enter into these debates and increasingly need to be literate in a range of disciplines other than just our own. The limits of our own disciplinary understandings are linked to the limits of others. Still, many of these debates seem dominated by the medical sciences-epidemiology, modelling, public health-while the social sciences remain, despite our best intentions, an afterthought.

\section{The Issue}

In the context of the need for interdisciplinary literacy, the Special Section in this issue is brought to us under the guest-editorial stewardship of Adriana Petryna and Sara Randell. The pieces gathered within (collated under the title 'The COVID Horizon') are written by physician-anthropologists at various stages in their careers. These articles are illustrative of the ways that, institutionally, medicine and anthropology have been imaginatively and practically combined in the US, namely through the MD-PhD programme in anthropology. This combined training in clinical medical training and anthropology allows these physicians to reach out 'beyond the walls of the clinical', as our guest editors frame it, to incorporate critical ideas of the social within an expanded interpretive field of action and reflection. Within the context then of their medical work, each of the five authors writes within what Petryna has called 'horizoning work', to imagine a bio-socially engaged medical practice for the future. Medicine within the domain of global and human rights in the US is the frame for Michelle Munyikwa's meditation on racial justice. Caroline Hodge, on the other hand, takes on the politics of space and social distancing and explains how they outline racial inequalities in the American Midwest. The question of how to relate to masks and the racial contexts of US public health is the topic of Chuan Hao (Alex) Chen's piece. Sara Rendell explores the role of medicine in 'contagious containment' against a history of criminalisation and immigration enforcement in the US. Finally, Joshua Franklin examines transgender inequalities and the reach of social medicine to foreground the limited capacity of medicine to address issues of social injustice. 
In addition, this edition of the journal features an obituary of René Devisch, written by Filip De Boeck and Sjaak van der Geest. He was the co-founder of the DutchBelgian journal Medische Antropologie [Medical Anthropology] in 1989, which was later transformed into MAT. We also have five research articles on a broad range of topics: Maria Concetta Lo Bosco writes on autism and the affect of mothers in the context of care and political capital in Portugal; Marie Kofod Svensson's article concerns outpatient clinics, chronic heart conditions, and uncertain futures in Denmark; Liana Chase explores the translation of psychosocial interventions within global mental health programmes among frontline health workers in Nepal; Helle Samuelsen and Lea Pare Toe reflect on how the public experience of COVID-19 in Burkina Faso was shaped by the country's political instability and ongoing security issues; and, finally, Lamia Moghnieh writes on the politics of trauma and the difficulties in diagnosis experienced by humanitarian psychiatrists in Lebanon.

The first Position Piece in this edition is by Oumy Baala Thiongane, and ponders deepening socio-economic inequalities in relation to accessing meningitis vaccines in Niger. The second, by Jordan Mullard, concerns the UK government's failure to address the disproportionate impact of COVID-19 on Black, Asian, and minority ethnic (BAME) groups in the UK. Jerome Crowder and Elizabeth Cartwright provide valuable insights into how photographic images and medical anthropology might be imaginatively and practically combined. Brittney $\mathrm{S}$. Mengistu, in Field Notes, writes about the ways in which the everyday experiences of women of the Eritrean diaspora are moulded by a mistrust of the Eritrean state, and about how this mistrust in turn impacted her fieldwork. Finally, within our Reviews section, readers will find Sjaak van der Geest's review of Aaron R. Denham's book on infanticide in Northern Ghana, and Rebekah Thompson's comparative review (the first in this section's new format) where she reflects on three monographs-the recent work of Lyle Fearnley, Frédéric Keck, and Natalie Porter-and the relationships between humans, animals, and zoonoses. 